\title{
(+)-USNIC ACID CONTENT AND ANTIOXIDANT ACTIVITY OF THREE LICHEN EXTRACTS
}

\author{
(C) Koptina A. ${ }^{1}$, Shcherbakova A. ${ }^{1}$, Soldati F. ${ }^{2}$, Gabdullin M. ${ }^{1}$, \\ Kanarskiy A. ${ }^{1}$, Ulrich-Merzenich G. ${ }^{3}$
}

\author{
${ }^{1}$ Mari State Technical University, Yoshkar-Ola, Russia \\ ${ }^{2}$ Pharmaton SA, 6934 Bioggio, Switzerland \\ ${ }^{3}$ Medical Clinic III, University of Bonn, Willhelmstr. 35-37, 53111 Bonn, Germany
}

Lichens produce a variety of secondary metabolites which belong to the depsides, depsidones, dibenzofurans and pulvinic acid derivative family. They proved to be a good source of natural antioxidants (1). Usnic acid uniquely found in many lichens has been reported to have analgesic, antimicrobial, anti-inflammatory, antiplatelet/antithrombotic, antiviral, cytotoxic/antiproliferative, gastroprotective, weight loss, and wound healing activity (2). We examined the (+)-usnic acid content and the anti-oxidative properties of the chloroform extract of lichen: Cladonia sylvatica (L.) Hoffm., Evernia prunastri (L.) Ach. and Usnea barbata (L.) Wigg. (s. I.) were collected in Mari El Republic of Russian Federation in June, 2011. Reverse phase HPLC analysis was carried out (Perkin Elmer Series 200 HPLC instrument; C18 column (C18; $25 \mathrm{~cm} \times 4.6 \mathrm{~mm}, 5 \mu \mathrm{m})$; UV/VID detector; solvent: methanol-water-phosphoric acid (80:20:.9, $\mathrm{v} / \mathrm{v} / \mathrm{v}))$. The sample injection volume was $20 \mu \mathrm{l}$ and the flow rate $1.0 \mathrm{~mL} / \mathrm{min}$. A standard of (+)-usnic acid was used. The total antioxidant activity of the extracts was evaluated by the phosphomolybdenum method as described Manojlovic et al. (3). The chloroform extracts of $C$. sylvatica, $E$. prunastri and U. barbata showed contents of $(+)$-usnic acid of $8.91 \pm 1.18$, $5.68 \pm 0.47$ and $74.49 \pm 8.64 \%$ respectively. The antioxidant activities were: $277.1 \pm 20.0,171.1 \pm 17.1$ and $205.8 \pm 7.2 \mathrm{mg}$ of ascorbic acid (AA) per $\mathrm{g}$ of extract respectively; In comparison, the antioxidant activity of the (+)-usnic acid standard was determined as $154 \pm 6.5 \mathrm{mg} \mathrm{AA} / \mathrm{g}$. We can report that $U$. barbata is a good source of (+)-usnic acid. Other secondary metabolites than (+)-usnic acid present in C. sylvatica and E. prunastri contribute to their high antioxidant activity and need to be further investigated.

References: (1)N. Verma,B.C. Behera, A. Joshi, Folia Microbiol (Praha) 57 (2012) 107. (2) Natural Standard Professional Monograph (2012). (3) N.T. Manojlovic, P.J. Vasiljevic, P.Z. Maskovic, M. Juskovic, G. Bogdanovic-Dusanovic, Evid Based Complement Alternat Med 2012 (2011) 452431.

\section{EXPERIMENTAL RESEARCH OF VEGETABLE DRUG «TABLETS FOR INTELLECT»}

\section{(c) Korsun V. F., Nikolaev S. M., Korsun E. V., Gulyaev S. M., Zhalsanov U. V.}

Institute of Phytotherapy, Moscow, Russia

Institute of general and experimental biology Siberian Department of Russian Academy of Science (SD RAS), Ulan-Ude, Russia, www.fitokor.ru

We developed the vegetable drug "Tablets for intellect", that contains roots of Scuttelaria baicalensis, Zinziber officinalis, Phodiola rosea, Rhaponticum carthamoides, herb of Schizonepeta multifida, Dracocephalum moldavica, Arnica montana, Melilotus officinalis, Astragalus membranaceus, Phlojodicarpus villosus, Bacopa monnieri and Inonotus obliquus. The aim of the research was detection of nootropic and psychoactivating qualities of "Tablets for intellect". Researchers used in the experiment intact rats of Wistar line of both sexes with initial mass 180-200 g. The rats were divided into 3 groups ( 7 animals in every group): first one was a check group; in second and third groups animals got a decoction, that was made of the tablets in doses of 100 and $300 \mathrm{mg} / \mathrm{kg}$ respectively. The test drug was injected intragastric once a day during 7 days before the experi- ment. Animals of the check group were injected with pure water in the similar amount in the same scheme. A level of motive and exploratory activities and emotional state of animals was determined in test "Open field" by the 7th day of the experiment. The installation "Open field" consisted of square area $100100 \mathrm{~cm}$ sized with walls measuring40 $\mathrm{sm}$. The area was divided by black lines into 25 (5 5) equal squares and was illuminated by lamp with power of $50 \mathrm{~W}$ that was hung above centre of the field at a height of $150 \mathrm{~cm}$. A rat was placed at the corner of installation, after then it was been supervising for 3 minutes: horizontal (number of crossed squares) and vertical (number of rises on hind legs) kinds of activities, number of episodes of grooming and defecation (according to number of defecation boluses) were registered. On the $7^{\text {th }}$ day of the experiment test of animals 